Original Research Article

\title{
A questionnaire based study of adverse drug effects of antiepileptic drugs in a tertiary care hospital in Central India
}

\author{
Mohini Sachin Mahatme ${ }^{1}$, Vartika Gupta ${ }^{1 *}$, Sachin Keshavrao Hiware ${ }^{1}$, \\ Mrunalini Milind Hardas ${ }^{2}$
}

${ }^{1}$ Department of Pharmacology, Indira Gandhi Government Medical College, Nagpur, Maharashtra, India ${ }^{2}$ Department of Medicine, Indira Gandhi Government Medical College, Nagpur, Maharashtra, India

Received: 11 October 2018 Accepted: 01 November 2018

*Correspondence to:

Dr. Vartika Gupta,

Email: vertika1510@gmail.com

Copyright: (C) the author(s), publisher and licensee Medip Academy. This is an openaccess article distributed under the terms of the Creative Commons Attribution NonCommercial License, which permits unrestricted noncommercial use, distribution, and reproduction in any medium, provided the original work is properly cited.

\begin{abstract}
Background: Epilepsy is a common disorder of brain function which affects around $1 \%$ of world population. Due to nature of chronicity of this disease, long term medical treatment with Anti-Epileptic Drugs (AEDs) is required to achieve control of the seizures. Antiepileptic drugs are responsible for 5\% of ADRs among all of the prescribed drugs. Due to the significant number of adverse drug reactions spontaneous reporting and knowledge about ADRs have gained the importance. Knowledge(K), attitude (A) and practices $(\mathrm{P})$ studies are preferred nowadays so as to have the better understanding and implication of the studies for the benefit of the patients. Therefore, this study was planned to evaluate Knowledge, Attitude and Practices (KAP) regarding Anti-Epileptic Drug (AEDs) therapy in epileptic patients and their relatives and to create awareness regarding the same.

Methods: A questionnaire based study for assessment of KAP during a period of 2 months in patients of epilepsy and their relatives.

Results: The maximum side effects were seen in central nervous system and functions $(80 \%)$ followed by dermatological problems $(6.57 \%)$, visual defects (5.19\%), GIT complaints (4.84\%) and lastly sexual function impairment (3.34\%). Carbamazepine was most commonly prescribed drug followed by phenytoin. Certain gender and age specific adverse events were found. 95\% patients were found to be compliant with medicines' dose and schedule.

Conclusions: The chronicity of epilepsy calls for long duration of treatment so consideration and addressing ADRs are essential to maintain compliance among patients.
\end{abstract}

Keywords: Adverse Drug Reactions, Antiepileptic drugs, Attitude, Knowledge, Practice

\section{INTRODUCTION}

Epilepsy is a common disorder of brain function which affects around $1 \%$ of world population. ${ }^{1}$ It is characterized by recurrent unprovoked and unpredicted occurrence of seizures. A seizure is a transient disturbance of cerebral function involving either a part or whole of the brain. ${ }^{2} \mathrm{~A}$ person predisposed to seizure has attacks when the basal level of excitability of the nervous system rises above a certain threshold. ${ }^{3}$ Epidemiological studies conducted in developing countries all over the world have shown high prevalence rate of epilepsy. ${ }^{4}$

Indian data shows general prevalence rate of 5.33 per 1000, with 5.11 and 5.47 in urban and rural areas respectively. ${ }^{5}$ 
Epilepsy has various aetiologies, which can be categorized according to age or causes irrespective of age or of idiopathic origin. The different causes among different age groups can be: in newborns (perinatal hypoxia, intracranial hemorrhage, metabolic disturbances etc), infants and children (febrile seizures, trauma or developmental disorders etc), adolescent and young adults (trauma, illicit drug use etc) and older adults (head injuries, brain tumors, alcohol withdrawal, cerebrovascular disease). ${ }^{6}$ Due to nature of chronicity of this disease, most patients with epilepsy depend on long term medical treatment with AntiEpileptic Drugs (AEDs) to achieve control of their seizures. ${ }^{7}$ Commonly used AEDs are carbamazepine, sodium valproate, phenytoin and phenobarbitone. ${ }^{8}$

AEDs have multifaceted pharmacological properties and narrow therapeutic index, leading to adverse drug reactions (ADRs) which often complicate proper choice of medication, requiring subsequent adjustment of therapy. ${ }^{9}$ The target of therapy should be full control of seizures with minimal or no adverse reactions attributed to medications to lead an optimal quality of life. ${ }^{10}$ ADRs deteriorates usual life style which can range from mild appetite and behavioural change to serious related problems like losing control over own actions and tremors, ineffective response when required. This contributes to a high number of morbidity and mortality. ${ }^{6}$ Antiepileptic drugs are responsible for $5 \%$ of ADRs among all of the prescribed drugs. Carbamazepine and phenytoin are the commonest among the group. ${ }^{11}$ Studies from USA and UK have reported that AEDs are associated with a significant number of ADRs and fatality. ${ }^{12,13}$ The extensive data regarding ADRs in Indian setup is still lacking. The newer reliable AEDs are also available in the Indian market and used at par with the older one like carbamazepine and phenytoin. Even the newer AEDs are also associated with numerous ADRs. ${ }^{14}$

Due to the significant number of adverse drug reactions of all the antiepileptic drugs spontaneous reporting and knowledge about ADRs have gained the importance. ${ }^{15}$ More and more preference is given to knowledge $(\mathrm{K})$, attitude $(\mathrm{A})$ and practices $(\mathrm{P})$ studies nowadays so as to have the better understanding and implication of the interpretation of such type of studies for the benefit of the patients. After extensive search knowledge (K), attitude (A) and practices $(\mathrm{P})$ studies are not available in epileptic patients and their relatives in India. Hence, this study was designed to assess the KAP of ADRs of AEDs in epileptic patients and their relatives.

\section{METHODS}

The questionnaire based study for assessment of knowledge, attitude and practices of ADRs of AEDs in epileptic patients and their relatives was conducted in medicine outpatient department of a tertiary care hospital for a duration of 2 months (May 2018-June 2018) in which study population consisted of the patients who have been diagnosed with epilepsy above the age of 14 years and above, guardians of epileptic patients who had cognitive impairment and those who signed the informed consent form. Patients with uncertain diagnosis of epilepsy, those who refused to sign the informed consent form and relatives of cognitively impaired patients who refused to sign were excluded from the study.

After approval from the Institutional Ethics Committee, patients and relatives of cognitively impaired patients who signed informed consent form were explained about the study. A set of 42 different pre-validated questions were asked in questionnaire. The questionnaire covered the basic history of patient's condition, various adverse effects involving different systems suffered by them and their practice towards those ADRs. ${ }^{16}$ Post data collection, information leaflets translated into vernacular language were given to patients about the basic knowledge of ADRs caused by the AEDs to create awareness. The leaflet contained list of common side effects which were to be reported and various dos and don'ts while taking the medications like following proper drug schedule, avoiding self-medication etc. were handed to patients. ${ }^{17}$ Being the tertiary care hospital, different AED like carbamazepine, phenytoin, phenobarbitone, clobazem, sodium valproate and clonazepam were provided free of cost to every patient for a period of 7 days. Folic acid was given along with these medications. Patients were again called for evaluation by the physician and for refill of the drugs. The patients were encouraged to meet the investigator in the follow-up visits.

\section{RESULTS}

There were 130 patients primarily approached for the KAP study, out of which 102 epileptic patients gave consent to participate in the survey. This included 58 male and 44 female patients.

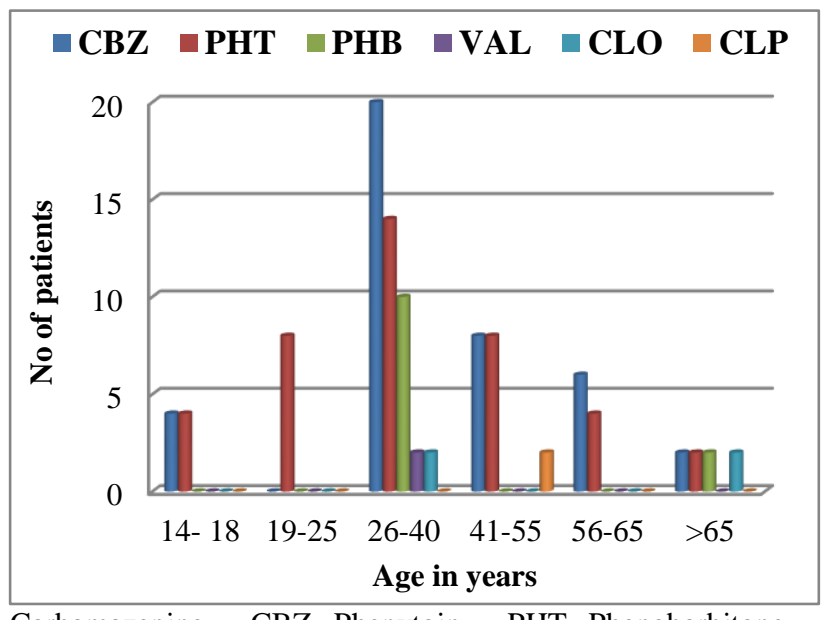

Carbamazepine $=\mathrm{CBZ}$, Phenytoin $=$ PHT, Phenobarbitone $=$ PHB Valproate $=\mathrm{VAL}$, Clobazem $=\mathrm{CLO}$, Clonazepam $=\mathrm{CLP}$

Figure 1: Age specific AEDS used in males.

Out of 102 patients on AED therapy maximum incidence was seen in age group 26-40 years. Age specific AED use 
in male and female is shown in (Figure 1 and 2). 60\% participants reported spontaneous origin of first attack of seizure associated with loss of consciousness along with forgetfulness of the rest of the events that took place afterwards. $30 \%$ patients had epilepsy since birth and the rest $10 \%$ patients acquired this condition while being under stress or due to some other causes like severe headache and head injuries.

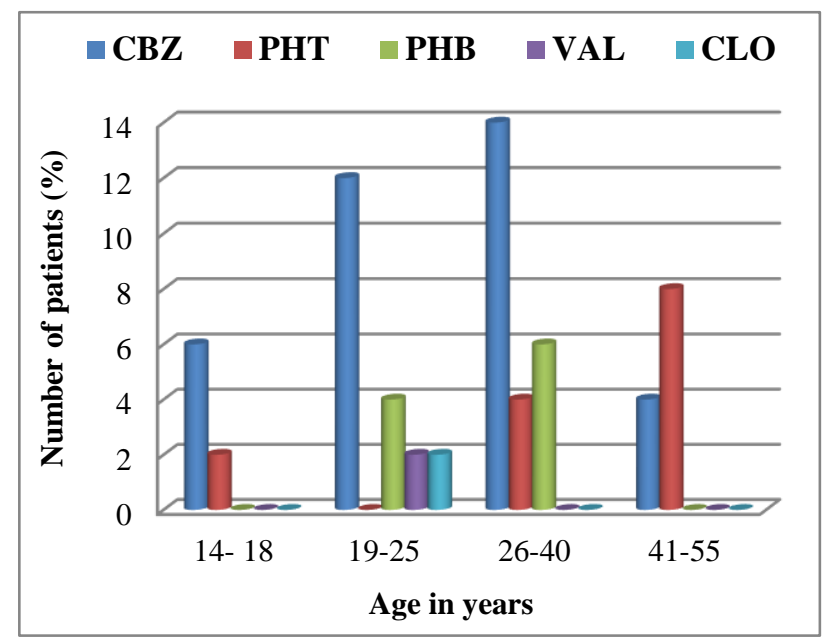

Carbamazepine $=$ CBZ, Phenytoin $=$ PHT, Phenobarbitone $=$ $\mathrm{PHB}$, Valproate $=\mathrm{VAL}$, Clobazem $=\mathrm{CLO}$

Figure 2: Age specific AEDS used in females.

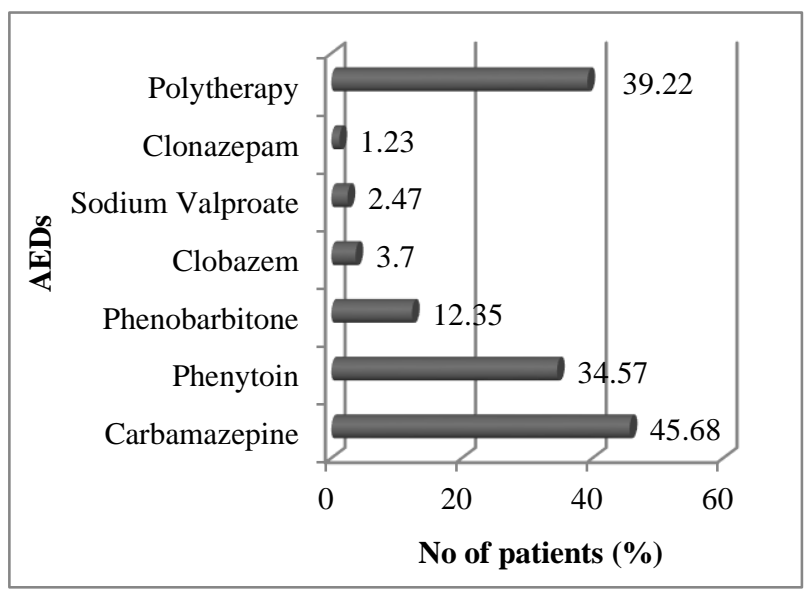

\section{Figure 3: Use of Anti Epileptic Drugs (AED)} in patients.

Carbamazepine was the commonest prescribed drug (47), followed by phenytoin (35), phenobarbitone (13), clobazam (3) and valproate (3). Clonazepam was the least prescribed drug. (Figure 3) $62(60.78 \%$ ) patients were on monotherapy and $40(39.22 \%)$ patients were on polytherapy. The most common combination used were carbamazepine and phenytoin followed by phenytoin and phenobarbitone.

Maximum incidences occurred in central nervous system and functions (80\%) followed by dermatological problems (6.57\%), visual defects $(5.19 \%)$, GIT complaints $(4.84 \%)$ and sexual function impairment (3.34\%). In CNS, motor function and coordination were commonest affected function system (Figure 4). Table 1 shows detailed analysis of CNS ADRs. Headache was the most common ADR i.e. $82.35 \%$ of total ADRs. Age and gender related variations were seen in this study. Younger patients complained more of irritability. Behavioural changes like increased irritation and aggressiveness were more prevalent in females whereas depressive symptoms i.e. staying worried for all day long and feeling miserable were more common in males.

Table 1: Central nervous system ADRs.

\begin{tabular}{|c|c|}
\hline & Patient \% \\
\hline Drowsiness and sleepiness & $76.47 \%$ \\
\hline Tiredness and lethargy & $70.59 \%$ \\
\hline $\begin{array}{l}\text { Inability to concentrate on same thing } \\
\text { for longer times }\end{array}$ & $66.67 \%$ \\
\hline $\begin{array}{l}\text { Incapability in performing daily } \\
\text { activities }\end{array}$ & $1.96 \%$ \\
\hline \multicolumn{2}{|l|}{ Increased irritability } \\
\hline Increased aggressiveness & $52.94 \%$ \\
\hline $\begin{array}{l}\text { Increased feeling of agitation and } \\
\text { restlessness }\end{array}$ & $60.78 \%$ \\
\hline $\begin{array}{l}\text { Constant feeling of pressure or over- } \\
\text { excitedness }\end{array}$ & $21.57 \%$ \\
\hline Increased irritation & $64.71 \%$ \\
\hline \multicolumn{2}{|l|}{ Depressive symptoms } \\
\hline Staying worried all days & $52.94 \%$ \\
\hline Feeling of depression and misery & $27.45 \%$ \\
\hline Decreased activeness & $52.94 \%$ \\
\hline Difficulty in sleeping & $21.45 \%$ \\
\hline \multicolumn{2}{|l|}{ Cognitive function } \\
\hline Difficulty in remembering names & $21.57 \%$ \\
\hline Increased forgetfulness of events & $13.72 \%$ \\
\hline Decreased concentration power & $62.74 \%$ \\
\hline $\begin{array}{l}\text { Ability to concentrate on something for } \\
\text { shorter period of times }\end{array}$ & $68.63 \%$ \\
\hline Slow reaction & $33.33 \%$ \\
\hline Slow speech & $33.33 \%$ \\
\hline Difficulty in expressing feelings & $35.29 \%$ \\
\hline Decreased power of thinking & $50.98 \%$ \\
\hline Difficulty in finding right words & $47.06 \%$ \\
\hline \multicolumn{2}{|l|}{ Motor problem and coordination } \\
\hline $\begin{array}{l}\text { Holding onto something to prevent } \\
\text { oneself from falling }\end{array}$ & $35.29 \%$ \\
\hline $\begin{array}{l}\text { Constantly walking into tables and } \\
\text { doorposts }\end{array}$ & $21.57 \%$ \\
\hline Dizziness & $74.51 \%$ \\
\hline Hands shake all the time & $33.33 \%$ \\
\hline $\begin{array}{l}\text { Hands shake when attempt to pick } \\
\text { something up }\end{array}$ & $62.74 \%$ \\
\hline Feeling of light-headedness & $72.55 \%$ \\
\hline Headache & $82.35 \%$ \\
\hline $\begin{array}{l}\text { Severe headache that prevents oneself } \\
\text { from doing anything }\end{array}$ & $39.22 \%$ \\
\hline
\end{tabular}


Cognitive functions such as difficulty in remembering names and events and in finding right words were observed more in males. In females, there was prevalence of severe headache which rendered them unable to work sometimes. Table 2 shows detailed analysis of other system ARDs.

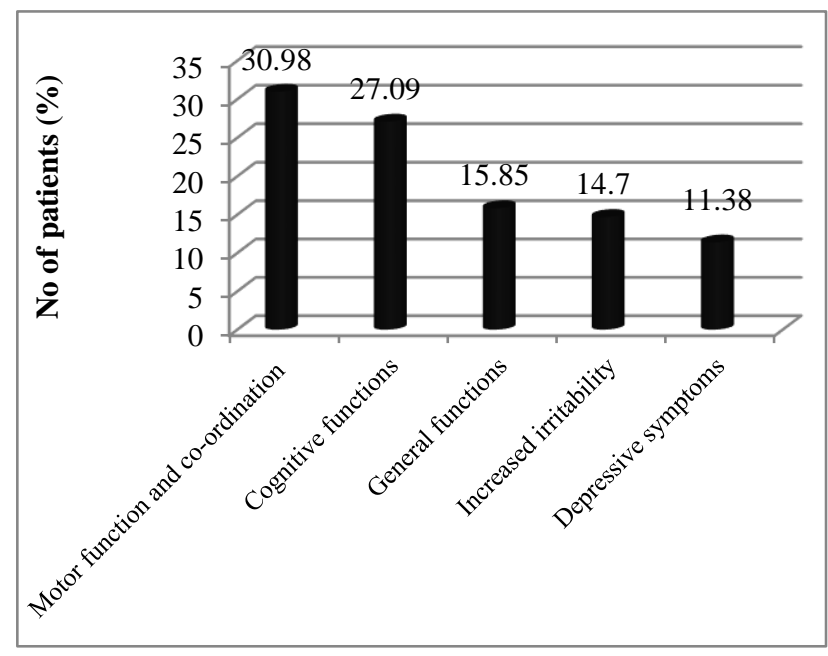

Figure 4: Distribution of different CNS related ADRs.

Table 2: Other system related ADRs.

\begin{tabular}{|ll|}
\hline Dermatological complaints & Patient \% \\
\hline Hypertrophy of gums & $31.37 \%$ \\
\hline Skin rash and skin acne & $21.57 \%$ \\
\hline Increased hair fall & $33.33 \%$ \\
\hline Increased salivation & $25.49 \%$ \\
\hline Gastrointestinal complaints & $33.33 \%$ \\
\hline Change in appetite & $31.37 \%$ \\
\hline Change in body weight & $1.96 \%$ \\
\hline Nauseous feeling & $15.69 \%$ \\
\hline $\begin{array}{l}\text { Abnormality in bowel movements } \\
\text { (constipation) }\end{array}$ \\
\hline Visual complaints & $27.45 \%$ \\
\hline Double visions(diplopia) & $60.78 \%$ \\
\hline Blurring of vision & \\
\hline Sexual functions & $21.45 \%$ \\
\hline Decrease in sexual desire & $21.45 \%$ \\
\hline Decrease in sexual gratification & $13.72 \%$ \\
\hline Irregularity in menses &
\end{tabular}

The compliance for the epileptic drugs observed among the patients involved in the survey was impressive. $95 \%$ patients took medications on time without missing a single dose. Only $5 \%$ manipulated the timings of their drug doses. $99 \%$ of subjects were unable to differentiate adverse drug reactions from side effects of AEDs prior to counselling. They had inability to differentiate whether the symptoms were due to drugs or were independent episodes. $54 \%$ participants contacted their doctors for adverse effects, $20 \%$ started self-medication and $26 \%$ waited for the adverse effects to subside on its own. Post counselling the participants were able to differentiate between adverse effects and side effects. $90 \%$ of subjects contacted their doctors for the same.

\section{DISCUSSION}

Epilepsy is a neurologically disturbed state of brain cells which doesn't have any age preference. There is no observed pattern for the occurrences of epileptic attacks or seizures, which may be spontaneous or unwarned. So, timely action by starting prompt treatment or management is essential. ${ }^{18}$

Monotherapy is preferred as standard management keeping in view less ADRs, cost, convenience, better compliance, adherence to standard treatment guidelines and lesser drug interactions. ${ }^{19}$ In this study, 62 patients were kept on single drug therapy and desired results were achieved.

The majority of the ADRs occurred with following AEDscarbamazepine, phenytoin and valproic acid. A similar AED prevalence pattern has been reported in other studies. ${ }^{20}$ The similar pattern might have been found due to easy availability of these AEDs throughout the study period.

In this study, CNS related ADRs (80\%) were the most frequently reported ADRs. The finding that CNS related ADRs is maximum correlates with other studies., ${ }^{9,21}$ Headache $(82.35 \%)$ was maximum reported symptom followed by drowsiness which was unlike other study conducted by Suman et al where sedation was the most frequent ADR i.e. $11.2 \%$ of total ADRs. ${ }^{9}$ This difference in CNS related symptoms can be due to the variation in study population and site.

Gum hypertrophy was reported with phenytoin. $31.37 \%$ patients taking phenytoin reported this ADR which correlates with results of previous studies, where incidence of gingival enlargement ranged from $3 \%$ to $93 \% .{ }^{11}$ The ADR may be a result of interaction of susceptible subpopulation of fibroblasts, keratinocytes and collagen with phenytoin and its metabolite, which can be prevented by maintaining good oral hygiene. The female participants complained of increased hair fall as compared to males. This can be due to fact that females have longer hair and are more observant hence notice it more often.

Gastrointestinal adverse effects occur due to direct effect of the drug on GIT. In this study, only $4.84 \%$ participants reported gastrointestinal adverse effects as they had been advised to take drugs along with meals. Appetite changes were more observed in females, particularly decrease in appetite, but abnormality in bowel movements such as constipation was seen more in males as compared to females. We were unable to correlate the findings of appetite changes and bowel movements. Visual and sexual function related side effects were not seen in younger subjects and those occurring were not gender specific. 
This disease majorly affects the quality of life of the patients; severity may extend to mental impairment because of repeated seizures. Few patients are even unable do their own daily activities. Due to the adverse drug reactions of antiepileptic drugs like sedation, drowsiness patients even skipped some doses so as not to feel drowsy during the day hours and to work properly. Females, especially, were seen more incompliant due to their marriage, families and society. The long duration of therapy caused some incompliance among patients but maximum of them were still docile. Attitude of patients and relatives was found quite negligent towards the sideeffects. They seemed to be reluctant about observing the symptoms.

The patients and their relatives were educated regarding various $\mathrm{ADRs}$ and vigilance regarding noticing and reporting of ADRs. Due to the information leaflets more and more patients were able to differentiate between ADRs and side effects which helped them in getting timely treatment for concerned adverse drug reaction.

The participants noticed and reported even the milder ADRs which were initially thought to be non significant. Majority of patients did not receive any treatment for the ADRs because either these reactions were mild and selflimiting in nature or there was no specific or symptomatic treatment for some reactions.

The adherence to the treatment which was interrupted earlier either due to the chronicity of the disease or due to the side effects of the disease increased after educating them about the simple measures like to take drugs with meals or to maintain oral hygiene. The change in the attitude of the patients and relatives even continued after the completion of the study.

Due to time constraint, larger sample population cannot be recruited in the study. Since the study data were abstracted from only one hospital, the results may not be generalizable to the entire population. The study results may reflect only ADRs in the institutions with similar patient demographics.

\section{CONCLUSION}

Epilepsy cannot be cured from its root. Due to its chronicity, unpredictable pattern, the treatment is often long term, prophylactic and targeted to prevent further episodes. This calls for regular medications with minimal or no adverse effects. However, with the active intervention like knowledge, awareness and simple instructions to patients some of the ADRs can be prevented or minimized.

Funding: No funding sources Conflict of interest: None declared

Ethical approval: The study was approved by the Institutional Ethics Committee

\section{REFERENCES}

1. Sharma HL, Sharma KK. Principles of Pharmacology. $3^{\text {rd }}$ ed.; Hyderabad: Paras Publication; 2017:523.

2. Papadakis MA, McPhee SJ. Rabow MW. Current Medical Diagnosis and Treatment. 57 th ed. New York: Mcgraw-Hill Education/ Medical publication; 2018:992.

3. Hall JE, Guyton AC. Textbook of Medical Physiology. $11^{\text {th }}$ edition. Philadelphia, PA: Elsevier; 2006:743.

4. World Health Organization. 1998. Primary prevention of mental, neurological and psychosocial disorders. Geneva: World Health Organization. Available at: http://www.who.int/iris/handle/10665/42043 (accessed on 15 / 08 /2018)

5. Santhosh NS, Sinha S, Satishchandra P. Epilepsy: Indian perspective. Annals of Indian Academy of Neurology. 2014 Mar;17(Suppl 1):S3.

6. Kasper DL, Fauci AS, Hauser SL, Longo DL, Jameson, JL, Loscalzo J. Harrison's Principles of Internal Medicine. $18^{\text {th }}$ edition. New York: McgrawHill Education/ Medical publication; 2012:3254-3256.

7. Mattson RH. Medical management of epilepsy in adults. Neurology. 1998 Nov 1;51(5 Suppl 4):S15-20.

8. Blume WT. Diagnosis and management of epilepsy. Can Med Associa J. 2003 Feb 18;168(4):441-8.

9. Suman A, Gosavi D. Study of Adverse Drug Effects of Antiepileptic Drugs used in Pediatric Patients in a Tertiary care rural Hospital-a Pharmacovigilance Study. J Youn Pharmac. 2017 Jan 1;9(1).

10. Vickrey BG, Hays RD, Rausch R, Sutherling WW, Engel Jr J, Brook RH. Quality of life of epilepsy surgery patients as compared with outpatients with hypertension, diabetes, heart disease, and/or depressive symptoms. Epilepsia. 1994 May;35(3):597-607.

11. Casetta I, Granieri E, Desiderá M, Monetti VC, Tola MR, Paolino E, et al. Phenytoin-induced gingival overgrowth: a community-based cross-sectional study in Ferrara, Italy. Neuroepidemiology. 1997;16(6):296303.

12. Le J, Nguyen T, Law AV, Hodding J. Adverse drug reactions among children over a 10-year period. Pediatrics. 2006 Aug 1;118(2):555-62.

13. Clarkson A, Choonara I. Surveillance for fatal suspected adverse drug reactions in the UK. Archives of disease in childhood. 2002 Dec 1;87(6):462-6.

14. Wong IC, Lhatoo SD. Adverse reactions to new anticonvulsant drugs. Drug Safety. 2000 Jul 1;23(1):35-56.

15. Sridharan R, Murthy BN. Prevalence and pattern of epilepsy in India. Epilepsia. 1999 May;40(5):631-6.

16. Kuzmanova RN, Stefanova IZ, Velcheva IV, Stambolieva KI. Translation, adaptation and validation of the Bulgarian version of the SIDAED questionnaire. J Biom Clin Resear. 2015 Jun $1 ; 8(1): 19-25$.

17. Kharkar M, Bowalekar S. Knowledge, attitude and perception/practices (KAP) of medical practitioners in 
India towards adverse drug reaction (ADR) reporting. Perspectives in clinical research. 2012 Jul;3(3):90.

18. Narayan SS, Sharma GK, Rodrigues RJ, Kulkarni C. Pattern of adverse drug reactions to anti-epileptic drugs: a cross-sectional one-year survey at a tertiary care hospital. Pharmacoepidemiology and Drug safety. 2008 Aug 1;17(8):807-12.

19. Shorvon SD, Chadwick D, Galbraith AW, Reynolds EH. One drug for epilepsy. Br Med J. 1978 Feb 25;1(6111):474-6.

20. Anderson M, Egunsola O, Cherrill J, Millward C, Fakis A, Choonara I. A prospective study of adverse drug reactions to antiepileptic drugs in children. BMJ open. 2015 May 1;5(6):e008298.
21. Varun T, Sebastian J, Ramesh A, Narahari MG, Bs K, Harsha S. Prospective Monitoring and Reporting of Adverse Drug Reactions associated with Antiplatelet and Antiepileptic Drugs in a South Indian Tertiary Care Teaching Hospital. Ind J Pha Practi. 2012;5(3).

Cite this article as: Mahatme MS, Gupta V, Hiware SK, Hardas MM. A questionnaire based study of adverse drug effects of antiepileptic drugs in a tertiary care hospital in Central India. Int J Basic Clin Pharmacol 2018;7:2336-41. 